\title{
Biópsias Transtraqueais \\ em Neoplasia do Mediastino: \\ Um Método Diagnóstico Viável
}

Transtracheal Biopsies in a Mediastinal Tumor:

A Viable Diagnostic Method

António Bugalho ${ }^{1,2,3}$, Cepeda Ribeiro ${ }^{1}$, Orlando Nunes ${ }^{4}$, Mónica Ferreira, ${ }^{5}$

Paula Borralho ${ }^{5,6}$, Manuela Bernardo ${ }^{4}$

Autor Correspondente:

António Bugalho [antonio.bugalho@jmellosaude.pt]

Travessa do Castro n³, 1350-070 Lisboa, Portugal

\section{RESUMO}

O diagnóstico de lesões pulmonares e mediastínicas pode ser realizado através de procedimentos minimamente invasivos dos quais se destaca a broncoscopia flexível e a ecoendoscopia brônquica. Descreve-se o caso de uma doente de 65 anos com lesão sólida no mediastino superior e médio em que o diagnóstico de cancro de pulmão de pequenas células foi alcançado por biópsia transtraqueal, um método não convencional mas viável.

PALAVRAS-CHAVE: Aspiração por Agulha Fina Guiada por Ecoendoscopia Brônquica; Biópsia por Agulha; Carcinoma de Pequenas Células do Pulmão; Endossonografia; Neoplasias do Mediastino

\section{ABSTRACT}

The diagnosis of lung and mediastinal lesions can be performed through minimally invasive procedures, namely flexible bronchoscopy and endobronchial ultrasound. We report the case of a 65-years-old woman with a solid lesion in the upper and middle mediastinum. The diagnosis of small cell lung cancer was accomplished by transtracheal biopsy, an unconventional but feasible method.

KEYWORDS: Biopsy, Needle; Small Cell Lung Carcinoma Endoscopic Ultrasound-Guided Fine Needle Aspiration; Endosonography; Mediastinal Neoplasms

1. Serviço de Pneumologia, CUF Infante Santo Hospital, Lisboa, Portugal. 2. Serviço de Pneumologia, CUF Descobertas Hospital, Lisboa, Portugal. 3. NOVA Medical School; Centro de Estudos de Doenças Crónicas (CEDOC), Lisboa, Portugal. 4. Serviço de Oncologia, CUF Infante Santo Hospital, Lisboa, Portugal. 5. Serviço de Anatomia Patológica, CUF Descobertas Hospital, Lisboa, Portugal. 6. Faculdade de Medicina da Universidade de Lisboa, ESTeSL, Lisboa, Portugal.

Recebido: 30/04/2017 - Aceite: 29/07/2017 


\section{INTRODUÇÃO}

O diagnóstico de lesões mediastínicas pode ser alcançado com procedimentos minimamente invasivos nomeadamente por punção transtraqueal com agulha fina (executada de forma não-guiada ou conduzida sob visualização direta por ecoendoscopia brônquica) ou biópsia aspirativa transtorácica guiada por métodos imagiológicos. Noutras situações é necessário recorrer a exames mais invasivos, dos quais se salienta a mediastinoscopia.

A ecoendoscopia brônquica com punção aspirativa é presentemente um exame diagnóstico de primeira-linha, face à segurança e elevada rentabilidade, sendo tradicionalmente realizada com agulhas 21G ou 22G que proporcionam a aquisição de material citológico. Por vezes, a quantidade e qualidade deste material não permite a realização de um diagnóstico seguro, particularmente nos casos de suspeita de linfoma, e pode ser insuficiente para caracterização molecular da neoplasia. A necessidade de material histológico de forma simples e eficaz gera a invenção de novas técnicas e equipamentos, que se encontram em fase de avaliação em alguns estudos científicos. $^{1-4}$ Descreve-se o caso clínico de uma doente com lesão mediastínica sólida em que se realizaram pela primeira vez biópsias transtraqueais com intuito diagnóstico.

\section{CASO CLÍNICO}

Apresenta-se o caso de uma doente do sexo feminino, com 65 anos de idade, caucasiana, fumadora (carga tabágica de 80 unidades-maço-ano), que recorreu ao Serviço de Urgência do Hospital CUF Infante Santo por dispneia de agravamento progressivo (mMRC 2), cansaço fácil, edema facial e cervical com cerca de um mês de evolução.

Ao exame objetivo salienta-se a presença de pletora facial, edema do membro superior direito e circulação colateral na face anterior do tórax, compatíveis com síndrome da veia cava superior. Sem adenopatias periféricas. Sem hepato ou esplenomegália.

A telerradiografia de tórax póstero-anterior demonstrou hipotransparência paratraqueal direita condicionando alargamento do mediastino médio e superior (Fig. 1). A tomografia computorizada (TC) do tórax com administração de contraste endovenoso (Fig. 2) evidenciou uma lesão mediastínica sólida, com 67 × 64 × 84 mm, em topografia paramediana direita, adiante e à direita da traqueia, abaixo do tronco braquiocefálico arterial, atrás do tronco braquiocefálico venoso esquerdo e da veia cava inferior, condicionando marcada redução de calibre destas estruturas vasculares. Na janela de pulmão identificou-se enfisema paraseptal de predomínio nos lobos superiores, sem lesões no parênquima pulmonar ou a nível infradiafragmático. Verificou-se, ainda, derrame pleural direito livre (9 mm) e derrame pericárdico (6 mm). A avaliação imagiológica cranioencefálica não evidenciou imagens sugestivas de envolvimento do sistema nervoso central.

A situação clínica da doente foi discutida em reunião multidisciplinar de Cancro do Pulmão, colocando-se como primeira hipótese diagnóstica a possibilidade de linfoma. Optou-se pela realização inicial de broncoscopia flexível e ecoendoscopia brônquica com punção aspirativa.

O exame endoscópico sob sedação anestésica revelou uma traqueia com dimensões e conformação normais, embora com discreta procidência da parede lateral direita por compressão extrínseca. Não existiam outras alterações endoluminais na árvore brônquica direita ou esquerda. Por ecoendoscopia foi visualizada uma formação hipoecogénica heterogénea, Doppler negativa, que se entendia entre as estações 2R, 4R e 10R, com 32 mm e compressão da veia cava superior (Fig. 3). Foram realizadas punções ecoguiadas com agulha de 21G, cujos

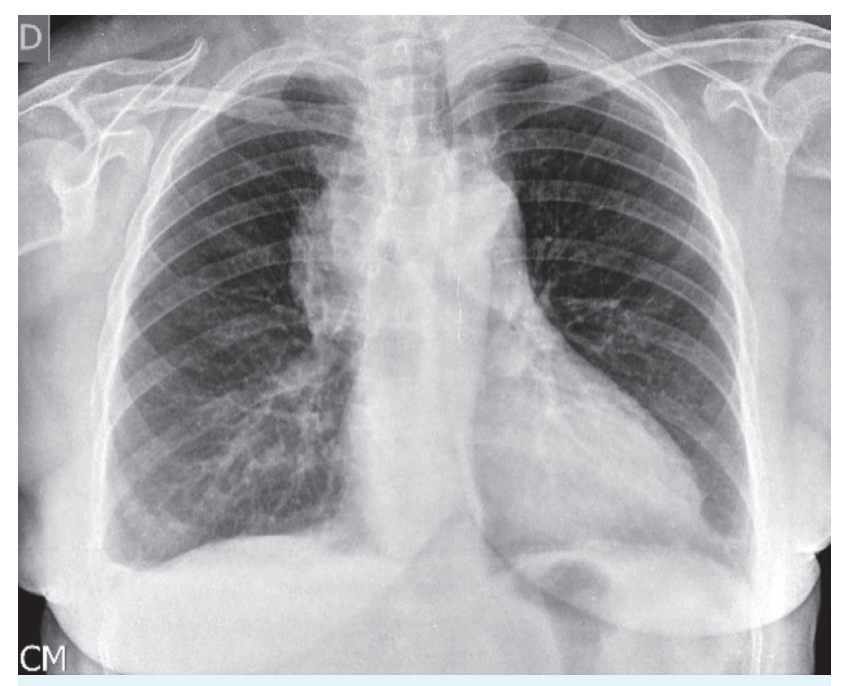

FIGURA 1. Telerradiografia de tórax com hipotransparência paratraqueal direita com alargamento do mediastino superior e médio.

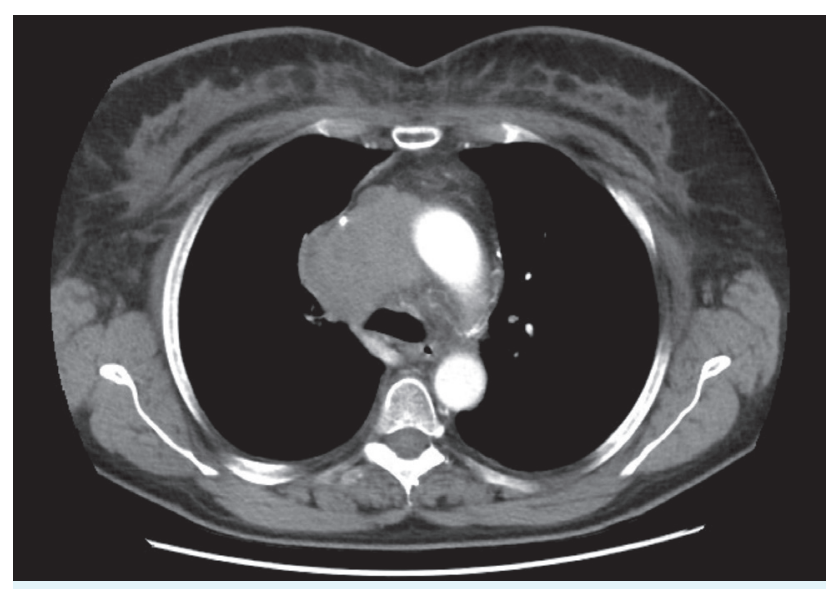

FIGURA 2. TC do tórax com lesão mediastínica com compressão da veia cava superior. 


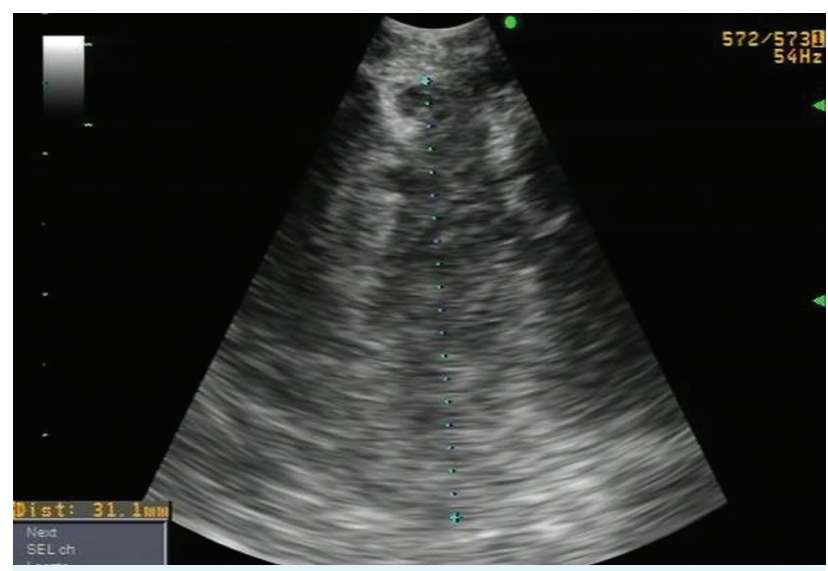

FIGURA 3. Imagem ecoendoscópica com visualização de formação hipoecogénica heterogénea paratraqueal.

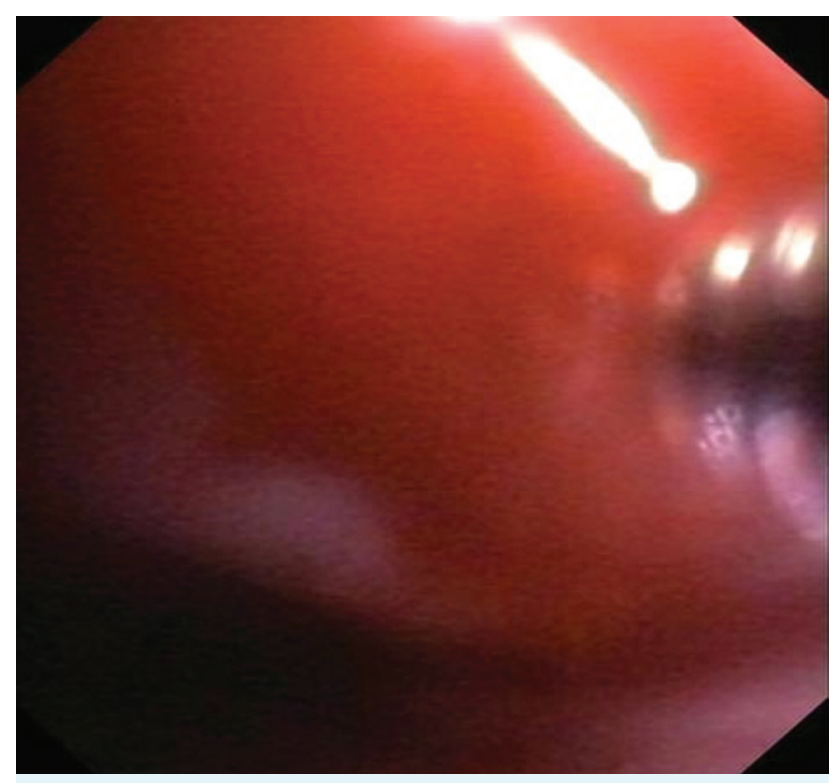

FIGURA 4. Inserção de pinça de biópsia através da parede lateral direita da traqueia para realização de biópsia transtraqueal.

aspirados foram colocados em formol para estudo citomorfológico e soro fisiológico para imunofenotipagem. A fragmentação do material, associada às dimensões da lesão, motivaram a tentativa de biópsias transtraqueais. Foi utilizada uma pinça de biópsia pediátrica que foi inserida pelo canal de trabalho do broncoscópio flexível e subsequentemente através da parede lateral direita da traqueia (Fig. 4), utilizando um dos orifícios da punção prévia com agulha fina. Este método possibilitou a aquisição de três fragmentos de biópsia que foram enviados para investigação anatomopatológica (Fig. 5). Não se verificaram complicações da técnica.

A imunofenotipagem das punções mediastínicas revelou a presença 95\% de células grandes CD45 negativas (correspondentes a elementos não hematológicos), CD56+, não sendo sugestiva a existência de neoplasia hematológica.

O material processado em citobloco detinha abundantes

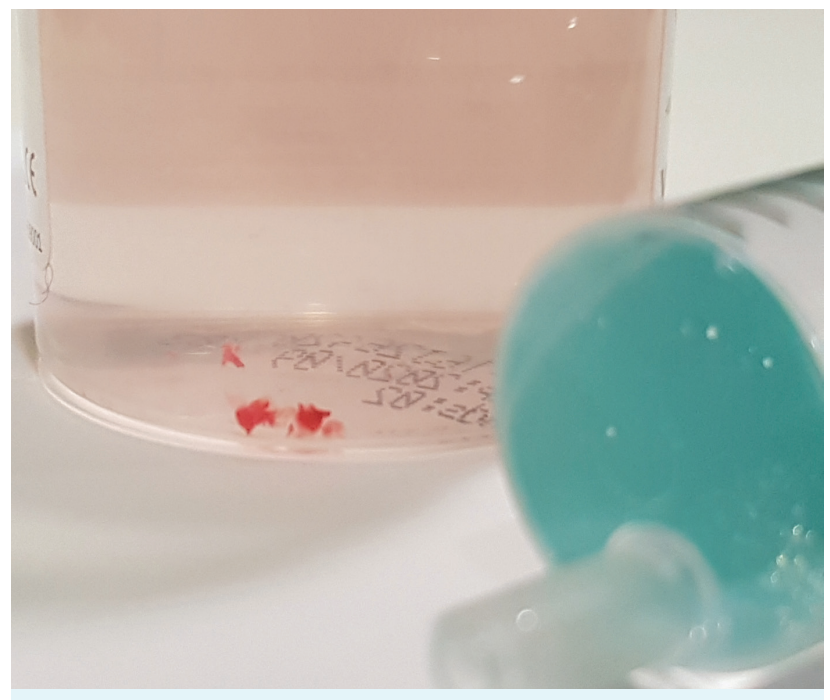

FIGURA 5. Fragmentos da lesão mediastínica obtidos por biópsia transtraqueal.

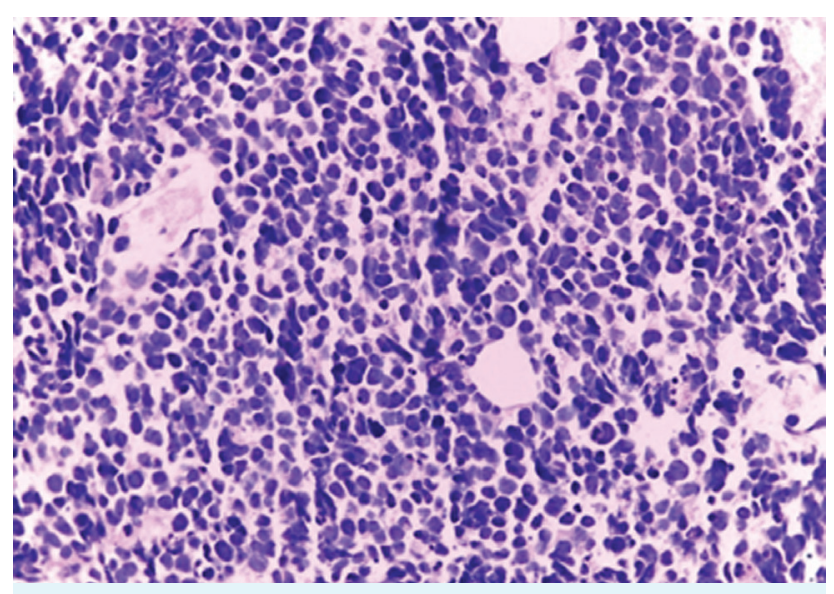

FIGURA 6. Biópsia transtraqueal demonstrando neoplasia constituída por células pequenas, redondas e azuis, com escasso citoplasma e cromatina em "sal e pimenta" (hematoxilina-eosina 400x).

células de dimensões pequenas a intermédias, mas com artefacto de esmagamento. As amostras histológicas eram constituídas por dois fragmentos de tecido neoplásico com células pequenas a intermédias, com escasso citoplasma e núcleos com cromatina fina em "sal e pimenta". Estas células eram sinaptofisina+, CD56+, AE1/ AE3+ em "dot" paranuclear, CD20-, CD3- e CD99-, com índice proliferativo (Ki67) de 100\%. Os aspetos morfológicos e imuno-histoquímicos foram consistentes com o diagnóstico de carcinoma do pulmão de pequenas células (Fig.s 6 e 7 ).

A doente foi avaliada em Consulta de Oncologia, tendo iniciado terapêutica com carboplatina e etoposídeo. Após o primeiro ciclo de quimioterapia verificou-se redução radiológica da lesão tumoral com desaparecimento do derrame pleural direito (Fig. 8), diminuição do edema do membro superior direito e do grau de dispneia (mMRC 1). 


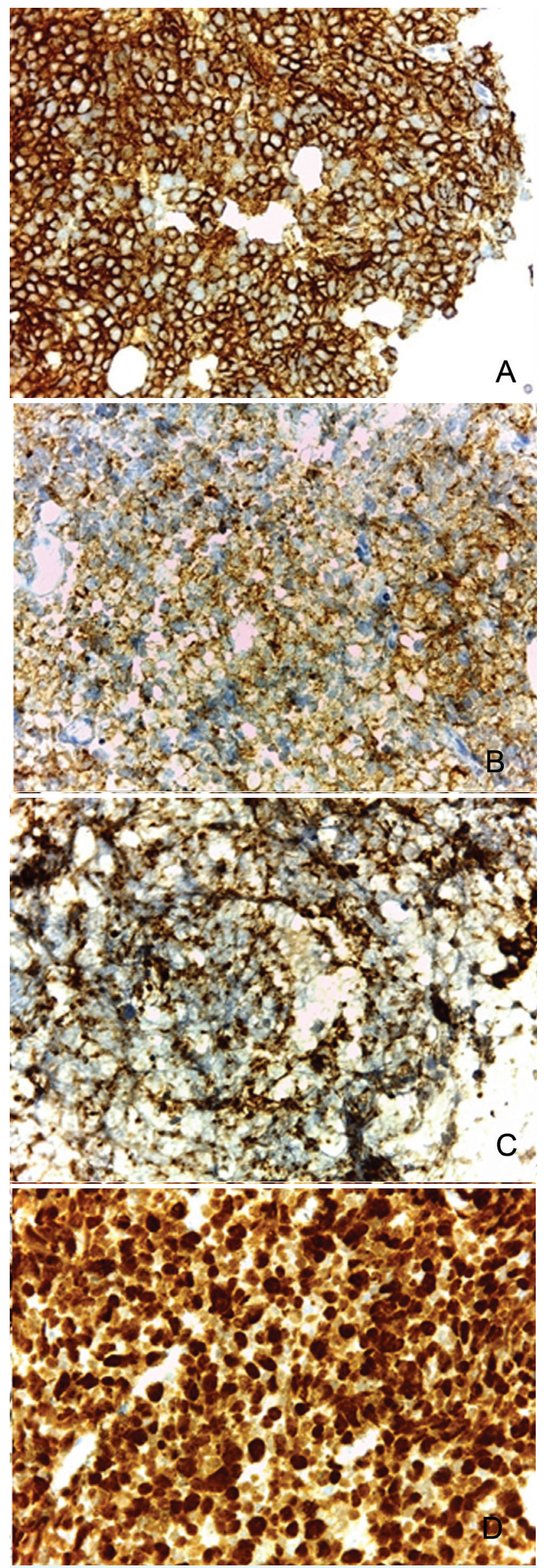

FIGURA 7. Diferenciação neuroendócrina em biópsia por imuno-histoquímica (400x): CD56 (A); Sinaptofisina (B); CK AE1/AE3 (C); Ki67 (D).
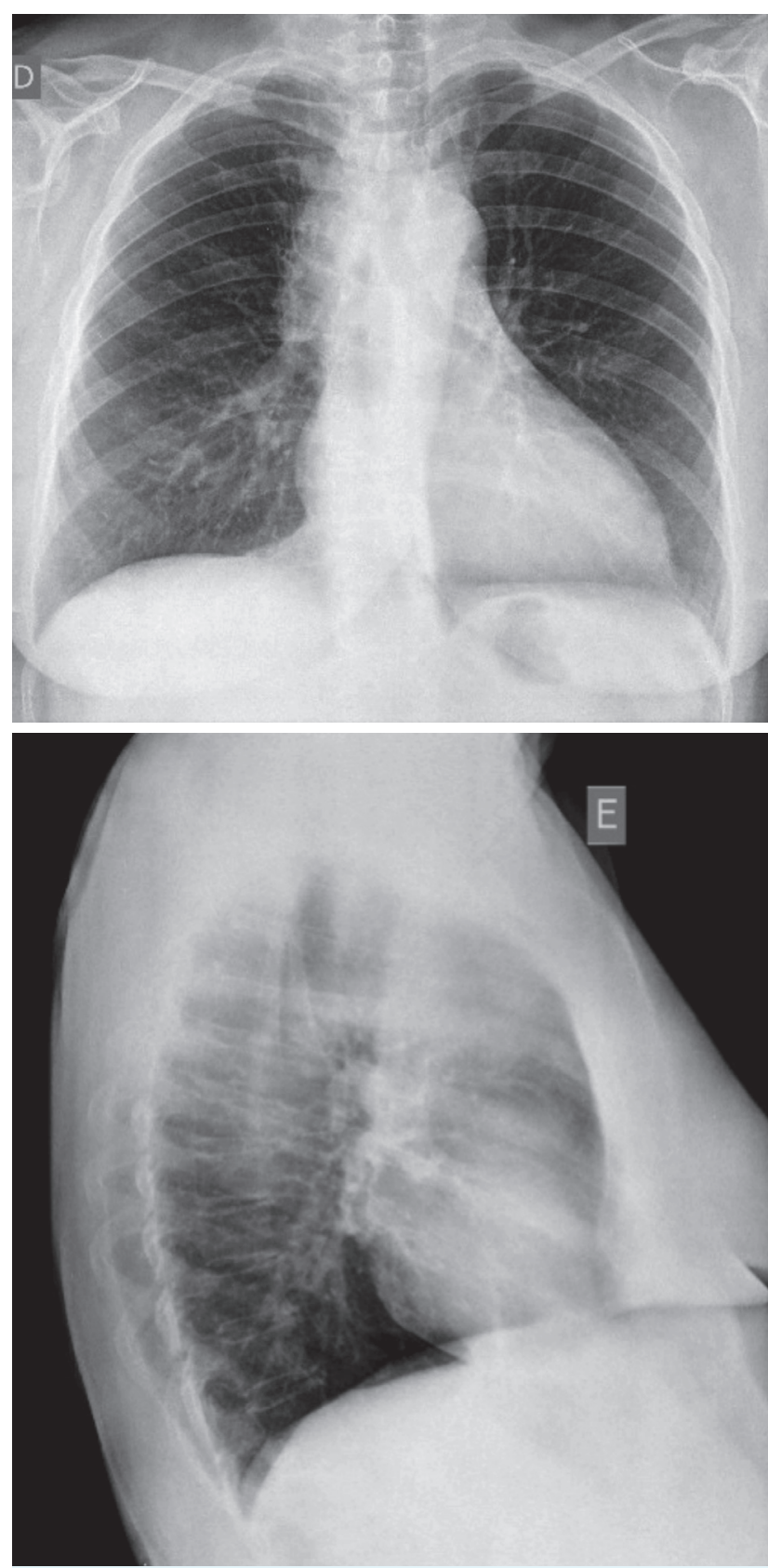

FIGURA 8. Reavaliação imagiológica por radiografia de tórax após primeiro ciclo de quimioterapia, documentando diminuição da lesão mediastínica.

\section{DISCUSSÃO}

Trata-se de uma doente com carcinoma do pulmão de pequenas células cujo diagnóstico foi alcançado por métodos minimamente invasivos. A particularidade deste caso reside no facto de terem sido efetuadas biópsias transtraqueais com recurso a pinça pediátrica adaptada, que proporcionaram o diagnóstico definitivo.

Alguns estudos piloto utilizaram uma pinça de biópsia, especialmente desenhada e descartável, para ser introduzida no canal de trabalho de um ecoendoscópio brônquico, facultando biópsias transtraqueais ou transbrônquicas ecoguiadas. Herth et $a^{1}$ em 2012 publicaram um trabalho que englobou 50 doentes com ade- 
nopatias mediastínicas PET (tomografia por emissão de positrões) positivas. Foi obtido material histológico com esta pinça em 45 casos obtendo-se um diagnóstico específico em 43 (86\%). Outros autores² demonstraram que a combinação desta mini-pinça associada à agulha de punção aspirativa convencional proporcionava uma precisão diagnóstica de 97\%. Em ambos os estudos ficou demonstrada a segurança do procedimento, não ocorrendo complicações. Também no presente caso não ocorreu qualquer complicação da biópsia transtraqueal, nomeadamente hemorragia, pneumotórax ou pneumomediastino.

Darwiche et al obtiveram amostras histológicas adequadas com a pinça de biópsia dedicada em 98\% dos casos, tendo aumentado a eficácia diagnóstica de 64\% para 93\% em patologia benigna, possibilitado a pesquisa de mutações EGFR e uma maior rentabilidade no diagnóstico de doença linfoproliferativa, comparativamente à punção aspirativa por agulha fina.

A pinça anteriormente referida1-3 nunca foi comercializada a nível mundial, motivo pelo qual não foi utilizada na presente doente. A realização de biópsia transtraqueal não-guiada em tempo real não é por nós advogada em todos os doentes com lesão mediastínica. Pode ser exequível quando: é executada por uma equipa experiente; após confirmação do local exato da lesão por ecoendoscopia brônquica; depois da utilização do Doppler para exclusão de estruturas vasculares adjacentes ou hipervascularização; e em situações em que a lesão se encontra adjacente à via aérea central e possui dimensões superiores a $20 \mathrm{~mm}$.

O desenvolvimento de outras técnicas de biópsia para lesões mediastínicas encontra-se em curso tal como veiculado numa publicação de 2016 que testou a eficácia e segurança de biópsias por cauterização assistida sob controlo de ecoendoscopia brônquica. ${ }^{4}$

\section{CONCLUSÃO}

A avaliação desta doente em equipa multidisciplinar e a correta articulação entre todos os seus elementos viabilizaram um diagnóstico definitivo e uma terapêutica célere.
CONFLITOS DE INTERESSE: Os autores declaram não ter qualquer conflito de interesse na realização do presente trabalho.

FONTES DE FINANCIAMENTO: Não houve qualquer fonte de financiamento na realização do presente trabalho.

CONFIDENCIALIDADE DOS DADOS: Os autores declaram ter seguido os protocolos da sua instituição acerca da publicação dos dados de doentes.

PROTEÇÃO DE PESSOAS E ANIMAIS: Os autores declaram que os procedimentos seguidos na elaboração do presente trabalho estão em conformidade com as normas das comissões de investigação clínica e de ética, bem como da declaração de Helsínquia e da Associação Médica Mundial.

CONFLICTS OF INTEREST: The authors declare that they have no conflicts of interest.

FINANCIAL SUPPORT: This work has not received any contribution, grant or scholarship.

CONFIDENTIALITY OF DATA: The authors declare that they have followed the protocols of their work center on the publication of data from patients.

PROTECTION OF HUMAN AND ANIMAL SUBJECTS: The authors declare that the procedures followed were in accordance with the regulations of the relevant clinical research ethics committee and with those of the Code of Ethics of the World Medical Association (Declaration of Helsinki).

\section{REFERÊNCIAS}

1. Herth FJ, Schuler H, Gompelmann D, Kahn N, Gasparini S, Ernst A, et al. Endobronchial ultrasound-guided lymph node biopsy with transbronchial needle forceps: a pilot study. Eur Respir J. 2012;39:373-7.

2. Chrissian A, Misselhorn D, Chen A. Endobronchial-ultrasound guided miniforceps biopsy of mediastinal and hilar lesions. Ann Thorac Surg. 2011;92:284-8.

3. Darwiche K, Freitag L, Nair A, Neumann C, Karpf-Wissel R, Welter S, et al. Evaluation of a novel endobronchial ultrasound-guided lymph node forceps in enlarged mediastinal lymph nodes. Respiration. 2013;86:229-36.

4. Bramley K, Pisani MA, Murphy TE, Araujo KL, Homer RJ, Puchalski JT. Endobronchial ultrasound-guided cautery-assisted transbronchial forceps biopsies: safety and sensitivity relative to transbronchial needle aspiration. Ann Thorac Surg. 2016;101:1870-6. 